\title{
Proteína degradável no rúmen e frequência de suplementação para recria de novilhos em pastejo
}

\section{Degradable protein in rumen and frequency of supplementation for it recreates of bovine in pasture}

\author{
Leonardo Vaz de Figueiredo Assad $^{1 *}$; Joanis Tilemahos Zervoudakis ${ }^{2}$; \\ Luciano da Silva Cabral'2; Luciana Keiko Hatamoto-Zervoudakis ${ }^{2}$; \\ Renata Pereira da Silva-Marques ${ }^{3}$; Jefferson Fabiano Werner Koscheck ${ }^{4}$; \\ Éder Rodrigues Toledo ${ }^{5}$; Marcus Vinicius Micheletti ${ }^{6}$
}

\begin{abstract}
Resumo
Objetivou-se avaliar o efeito da proteína degradável no rúmen (PDR) e frequência de suplementação sobre o consumo e digestibilidade dos nutrientes, concentração de nitrogênio amoniacal $\left(\mathrm{N}^{-\mathrm{NH}_{3}}\right), \mathrm{pH}$ ruminal e compostos nitrogenados excretados na urina (NUR) e sérico (NS) em bovinos em pastagem de Brachiaria brizantha cv. Marandu durante o período de transição águas-seca. Foram utilizados cinco bovinos mestiços, castrados, com peso corporal médio inicial de $350 \mathrm{~kg}$, fistulados no rúmen. Utilizouse o delineamento em quadrado latino 5 X 5, com duração de 21 dias cada período experimental. Os tratamentos avaliados foram: SAL - mistura mineral fornecida ad libitum (Controle); PDR diário - suplemento formulado para atendimento das exigências em PDR, com fornecimento diário; PDR frequência- suplemento formulado para atendimento das exigências em PDR fornecido três vezes por semana ( segundas, quartas e sextas -feiras); PDR+ - suplemento formulado com acréscimo de $10 \%$ nas exigências em PDR fornecido 3X; PDR- - suplemento formulado com 10\% a menos da exigência em PDR fornecido 3X. Verificou-se diferença estatística para os consumos de matéria seca (CMS), forragem (CFO) e fibra em detergente neutro (CFDN) e para digestibilidade aparente da MS e FDN com efeito de tratamento $(\mathrm{P}<0,05)$, sendo posteriormente verificado pela análise de contraste estatisticamente significativo $(\mathrm{P}<0,05)$ entre os suplementos (Sal vs. PDR diário). O fornecimento de suplementação múltipla com acréscimo ou redução em $10 \%$ nas exigências em PDR dos animais e com frequências controladas do suplemento não afetou $(\mathrm{P}>0,05)$ o CMS e a digestibilidade aparente da MS, PB e FDN. $\mathrm{O} \mathrm{pH}$ ruminal apresentou diferença entre os suplementos PDR frequência vs. PDR- no tempo 4 horas em dia de não suplementação. A concentração de amônia ruminal dos animais suplementados apresentou diferença entre os suplementos PDR diário vs. PDR frequência; PDR frequência vs. PDR+; PDR frequência vs. PDR-. A concentração de nitrogênio sérico é maior $(\mathrm{P}<0,05)$ em animais consumindo suplementos múltiplos com acréscimo de $10 \%$ das exigências de PDR.
\end{abstract}

Palavras-chave: Amônia, consumo, digestibilidade, suplementos múltiplos

\footnotetext{
${ }^{1}$ M.e em Ciência Animal, Universidade Federal de Mato Grosso, UFMT, Cuiabá, MT. E-mail: leo.assad@gmail.com

2 Profs. Drs., UFMT, Cuiabá, MT. E-mail: joanis@ufmt.br; cabralls@ufmt.br; lukeiko@yahoo.com.br

3 Discente de Doutorado em Ciência Animal, UFMT, Cuiabá, MT. E-mail: renatinharps@hotmail.com

${ }^{4}$ Discente de Doutorado em Zootecnia, Universidade Estadual Paulista, UNESP, Jaboticabal, SP. E-mail: jeffersonfwk@hotmail.com

${ }^{5}$ Médico Veterinário, Cuiabá, MT. E-mail: toledovet@gmail.com

${ }^{6}$ M.e em Ciência Animal, UFMT, Cuiabá, MT. E-mail: michieletto@gmail.com

* Autor para correspondência
} 


\begin{abstract}
It was aimed to evaluate the effect of the rumen degradable protein (RDP) and supplementation frequency on the consumption and digestibility of the nutrients, concentration of amoniacal nitrogen $\left(\mathrm{N}^{-\mathrm{NH}_{3}}\right)$, ruminal $\mathrm{pH}$ and nitrogen compounds excreted in the urine (NUR) and serum (NS) in bovine in pasture of Brachiaria brizantha cv. Marandu during the rainy/dry transition period. Five crossbred steers, castrated, with average body weight of $350 \mathrm{~kg}$, cannulated in the rumen, were used. The experiment used in Latin square design 5 X 5, with duration of 21 days each experimental period. The treatments were: SAL - mineral mix supplied ad libitum (Controls); daily RDP: supplement formulated to meet the requirements RDP, with daily supply; frequency RDP: supplement formulated to meet the requirements RDP, supplied three times on week (Mondays, Wednesdays and Fridays); RDP+: supplement formulated with increment of $10 \%$ of the requirements of RDP supplied 3X; RDP-: supplement formulated with less $10 \%$ of the requirements of RDP supplied $3 \mathrm{X}$. There was statistical difference for dry matter intake (DMI), forage (CFO) and neutral detergent fiber (NDF) and apparent digestibility of DM and NDF with treatment effect $(\mathrm{p}<0.05)$, after being checked by statistically significant contrast analysis $(\mathrm{p}<0.05)$ between supplements (Ps vs. RDP daily). Providing multiple supplementation increased or reduced by $10 \%$ in RDP requirements of animals and controlled add-frequency did not affect $(\mathrm{P}>0.05) \mathrm{DMI}$ and apparent digestibility of DM, CP and NDF. The ruminal $\mathrm{pH}$ was different between the frequency RDP supplements vs. RDP- time 4 hours on day no supplementation. The ruminal ammonia concentration of the supplemented animals showed a difference between the RDP daily supplements vs. RDP frequency; RDP frequency vs. RDP +; RDP frequency vs. PDR-. The nitrogen serum concentration is larger ( $\mathrm{P}<$ 0.10 ) in animals consuming multiple supplements with increment of $10 \%$ of the requirements of RDP.

Key words: Ammonia, consumption, digestibility, multiple supplements
\end{abstract}

\section{Introdução}

A suplementação concentrada de bovinos é uma das principais tecnologias utilizadas para maximizar a produção de carne no sistema produtivo que possui as gramíneas tropicais como substrato básico da alimentação. A manipulação nutricional através da suplementação da dieta representa uma forma de proporcionar uma otimização do desempenho dos animais criados a pasto, por meio de estímulos da atividade microbiana ruminal, onde o nível de manipulação dependerá basicamente do desempenho projetado para os animais (REIS et al., 2005).

O fornecimento via suplemento de proteína degradável no rúmen (PDR) pode promover melhorias no desempenho dos bovinos, pois acarreta em aumento do suprimento de amônia e energia potencializando o crescimento dos microrganismos ruminais, e consequentemente, otimizando o consumo de forragem e digestibilidade no rúmen resultando em maior suprimento de nutrientes aos bovinos, fazendo com que as exigências nutricionais dos mesmos possam ser atendidas (PAULINO et al., 2004).

Porém, apesar dos microrganismos ruminais utilizarem amônia para seu crescimento, em muitos casos a velocidade de produção pode exceder a de utilização, aumentando a excreção de compostos nitrogenados e o custo energético da síntese de ureia pelo fígado (RUSSELL et al., 1992). Uma vez liberada para o sangue, a ureia é excretada na urina ou reciclada para o rúmen através da saliva ou por difusão através da parede ruminal (VAN SOEST, 1994).

Devido à estreita relação entre maximização da atividade microbiana e a melhoria no desempenho produtivo dos bovinos em pastejo, a manipulação nutricional da dieta deve atender primeiramente as exigências nutricionais dos microrganismos ruminais. Sendo assim, o conhecimento das exigências nutricionais bem como das condições favoráveis para o crescimento microbiano são fundamentais para que os ruminantes utilizem de maneira mais eficiente os carboidratos fibrosos dos 
pastos (REIS et al., 2005).

Objetivou-se com este estudo avaliar o efeito da proteína degradável no rúmen em suplementos múltiplos distribuídos de forma com diferentes frequências sobre os parâmetros nutricionais de bovinos recriados em pastagem de Brachiaria brizantha cv. Marandu durante o período de transição águas-seca.

\section{Material e Métodos}

O experimento foi conduzido no setor de Bovinocultura de Corte, durante o período de transição águas-seca do ano, entre os meses de março e junho. Para a avaliação dos parâmetros nutricionais, foram utilizados cinco novilhos mestiços $1 / 2$ Europeu $\times$ Zebu castrados, com idade e peso corporal médio inicial de aproximadamente 22 meses e $350 \mathrm{~kg}$, respectivamente, canulados no rúmen. Antes do início do experimento, todos os animais foram submetidos ao controle de endo e ectoparasitas.

A área experimental foi constituída de cinco piquetes de 0,24 há cada, cobertos uniformemente com Brachiaria brizantha cv. Marandu, providos de bebedouros e cochos cobertos.

Foram avaliados cinco tratamentos experimentais, sendo:

SAL - mistura mineral fornecida ad libitum (Tratamento Controle);

PDR diário - Suplemento formulado para atendimento das exigências em proteína degradável no rúmen (PDR) de acordo com Valadares Filho, Paulino e Magalhães (2006), com fornecimento diário;

PDR frequência- Suplemento formulado para atendimento das exigências em proteína degradável no rúmen (PDR) de acordo com Valadares Filho, Paulino e Magalhães (2006), com fornecimento em três vezes por semana( segundas, quartas e sextas feiras);

PDR+- Suplemento formulado com acréscimo de $10 \%$ das exigências em proteína degradável no rúmen (PDR) com fornecimento em três vezes por semana (segundas quartas e sextas feiras);

PDR- - Suplemento formulado com 10\% a menos da exigência de PDR, com fornecimento em três vezes por semana (segundas, quartas e sextas feiras) (Tabela 1).

Tabela 1. Composição percentual dos suplementos expressa com base na matéria natural e valores de proteína bruta e nutrientes digestíveis totais com base na matéria seca.

\begin{tabular}{lcccc}
\hline \multirow{2}{*}{\multicolumn{1}{c}{ Ingredientes }} & \multicolumn{4}{c}{ Suplementos } \\
\cline { 2 - 4 } \multicolumn{1}{c}{ Farelo de soja } & PDR & PDR + & PDR - & SAL \\
Milho Grão Moído & 25,0 & 34,0 & 9,5 & - \\
Ureia/Sulfato de amônia (9:1) & 63,5 & 53,5 & 79,5 & - \\
Mistura Mineral 1 & 1,5 & 2,5 & 1,0 & - \\
PB & 10,0 & 10,0 & 10,0 & 100,0 \\
NDT & 23,01 & Composição (\% MS) & - \\
\hline
\end{tabular}

1/ Mistura mineral comercial - Níveis de garantia: cálcio $198 \mathrm{~g}$; fósforo $60 \mathrm{~g}$; sódio $117 \mathrm{~g}$; magnésio 5,1g; enxofre $12,6 \mathrm{~g}$; iodo $17,7 \mathrm{mg}$; ferro 425mg; selênio 10,4mg; cobalto $80 \mathrm{mg}$; manganês $527 \mathrm{mg}$; flúor $600 \mathrm{mg}$; cobre $1.000 \mathrm{mg}$ e zinco $3.000 \mathrm{mg}$.

Fonte: Elaboração dos autores. 
Os suplementos múltiplos foram balanceados considerando as exigências em PDR e nutrientes digestíveis totais (NDT) de bovinos zebuínos machos, não castrados, com peso vivo médio de 350 $\mathrm{kg}$, para ganho de peso de 1,0 kg/dia de acordo com Valadares Filho, Paulino e Magalhães (2006).

Os suplementos foram fornecidos em quantidades equivalentes a $1 \mathrm{~kg} / \mathrm{animal} / \mathrm{dia}$, em duas frequências semanais (diariamente e três vezes por semana) e sempre às 10:00 horas, a fim de minimizar as interferências no comportamento de pastejo dos animais, mais pronunciado no início da manhã e fim da tarde (ADAMS, 1985). Os animais suplementados três vezes por semana (segundas, quartas e sextas - feiras) receberam a mesma quantidade semanal de suplementos que os animais suplementados diariamente, o que significa 2,333 $\mathrm{kg}$ de suplemento nos dias de suplementação.

Os animais foram pesados sem jejum no início do experimento e a cada final de período experimental, para acompanhamento do desempenho e do consumo em função do peso corporal. Após a pesagem inicial, os animais receberam aleatoriamente os tratamentos e no final de cada período os animais foram rotacionados nos piquetes e nos tratamentos, permitindo que todos animais recebessem todos os tratamentos e fossem alojados em todos os piquetes ao final do experimento.

$\mathrm{O}$ experimento foi delineado em quadrado latino (5x5), com cinco tratamentos e cinco períodos experimentais com duração de 21 dias cada, sendo que os sete primeiros dias foram destinados à amostragem da forragem e adaptação dos animais às condições experimentais.

Foram realizadas coletas de amostras dos suplementos utilizados durante o preparo das misturas para as análises laboratoriais. No primeiro dia de cada período experimental foram realizadas coletas de amostras de forragem nos diferentes piquetes, através do corte, a $5 \mathrm{~cm}$ do solo, de 5 áreas delimitadas por um quadrado metálico de 0,5 x 0,5 $\mathrm{m}$, escolhidos aleatoriamente para a determinação da massa de forragem seca total (MFST) e massa de forragem seca potencialmente digestível (MFSpD).

Após a coleta, as amostras de cada piquete foram pesadas e homogeneizadas, e a partir dessas formas retiradas duas alíquotas compostas: uma para avaliação da MFST/ha e outra para fracionamento dos componentes estruturais da planta e posterior análise das disponibilidades por hectare de massa de folha verde (MFV), folha seca (MFS), colmo verde (MCV) e colmo seco (MCS). A amostragem da forragem consumida pelos animais foi obtida via simulação manual do pastejo, realizada no $1^{\circ}$ dia de cada período experimental.

Das amostras destinadas à estimativa da disponibilidade total de MS de forragem, foi determinado o resíduo insolúvel em detergente neutro avaliado após incubação in situ das amostras por 240 horas (CASALI et al., 2008), para cálculo do percentual de MS potencialmente digestível (MSpD) disponível aos animais. Esse resultado foi estimado por intermédio da seguinte equação:

$$
M S p D=0,98 X(100-F D N)+(F D N-F D N i) \quad \text { (1) }
$$

Em que: $0,98=$ coeficiente de digestibilidade verdadeiro do conteúdocelular; FDNi $=$ FDN indigestível.

Para a estimativa da excreção de MS fecal, foi utilizado a LIPE $®$ (Lignina Purificada e Enriquecida), na quantidade de 0,5 gramas, acondicionado na forma de cápsulas e introduzido diretamente no rúmen em dose única diária as 14:00h, a partir do $8^{\circ}$ dia do período experimental e estendendo-se até o $14^{\circ}$ dia (dois dias de adaptação e cinco dias de coleta). A coleta de amostra de fezes foi feita diretamente na ampola retal do animal, em sacos plásticos devidamente identificados, durante cinco dias consecutivos. Estas amostras foram congeladas e ao final de todas as coletas foi formada uma amostra composta de cada animal por período.

Posteriormente, as amostras de fezes e da simulação de pastejo foram pré-secas em estufa 
de ventilação forçada $\left(60^{\circ} \mathrm{C}\right)$ por 72 horas, sendo estas moídas em moinho de facas com peneira com malha de 1,0 mm, compostas por animal/período e armazenadas em frascos de plásticos devidamente identificados para análises laboratoriais.

A determinação da LIPE® foi realizada por espectroscopia no infravermelho, sendo a concentração do indicador nas fezes obtida pela razão logarítmica das bandas espectrais entre determinados comprimentos de onda (SALIBA et al., 2005).

A concentração de fibra em detergente neutro indigestível (FDNi) foi determinada nas amostras de pastejo simulado, suplementos e fezes por intermédio da digestibilidade in situ, obtida após incubação por 240 horas (CASALI et al., 2008) no rúmen de um bovino mestiço com $400 \mathrm{~kg}$ de peso corporal.

Para estimativas do consumo voluntário de MS dos animais foi utilizada a equação proposta por Detmann et al. (2001):

$C M S=[(E F \times C I F)-I S] \div C I F O+C M S S$

Em que: $\mathrm{CMS}=$ consumo de matéria seca; EF $=$ excreção fecal $(\mathrm{kg} / \mathrm{dia}) ; \mathrm{CIF}=$ concentração do indicador nas fezes $(\mathrm{kg} / \mathrm{kg})$; IS = indicador presente no suplemento $(\mathrm{kg} / \mathrm{dia}) ; \mathrm{CIFO}=$ concentração do indicador na forragem $(\mathrm{kg} / \mathrm{kg})$ e CMSS = consumo de matéria seca de suplemento ( $\mathrm{kg} / \mathrm{dia})$;

No oitavo dia, quatro horas após o fornecimento do suplemento, foram realizadas as coletas de sangue e urina dos animais para determinação de ureia e creatinina. Após a coleta, o sangue foi centrifugado a $4000 \mathrm{rpm}$, durante 15 minutos para a extração do soro, que foi congelado a $-20^{\circ} \mathrm{C}$ para posterior quantificação dos teores de creatinina e ureia (VALADARES et al., 1999).

As coletas de urina, na forma de amostra "spot", foram realizadas no momento da micção espontânea dos animais, sendo armazenadas duas alíquotas; a primeira, destinada à determinação da concentração de creatinina que constituiu-se de $15 \mathrm{~mL}$ de urina e $135 \mathrm{~mL}$ de ácido sulfúrico 0,036 N, segundo padronização de Valadares et al. (1999). A segunda foi destinada à determinação da concentração de $\mathrm{N}$ total urinário e foi constituída de $100 \mathrm{~mL}$ de urina e $1 \mathrm{~mL}$ de ácido sulfúrico $36 \mathrm{~N}$. As amostras foram imediatamente congeladas a $-20^{\circ} \mathrm{C}$ (VALADARES et al., 1999).

Para determinar o $\mathrm{pH}$ e concentração de amônia $\left(\mathrm{N}-\mathrm{NH}_{3}\right)$ no líquido ruminal, as amostras foram coletadas manualmente, do $15^{\circ}$ ao $21^{\circ}$ dia do período experimental (perfil semanal), imediatamente antes da suplementação e 4 horas após o fornecimento do suplemento (10:00 e 14:00 h, respectivamente), na região de interface líquido/sólido do ambiente ruminal e filtradas por uma camada tripla de gaze. As análises de $\mathrm{pH}$ foram feitas imediatamente após a coleta por intermédio de peagâmetro digital. Para a determinação de amônia, separou-se uma alíquota de $50 \mathrm{~mL}$ de líquido ruminal que foi fixada com $1 \mathrm{~mL}$ de $\mathrm{H}_{2} \mathrm{SO}_{4}$ 1:1, sendo acondicionada em recipiente de plástico com tampa, identificada e congelada a $-20^{\circ} \mathrm{C}$.

Para relacionar o consumo ao peso vivo (PV) dos animais, foi utilizado como referência o peso médio no período, estimado pela média entre os valores inicial e final de cada período.

As determinações da MS, proteína bruta (PB), fibra em detergente neutro (FDN), fibra em detergente ácido (FDA) e extrato etéreo (EE) foram realizados de acordo com descrições de Silva e Queiroz (2002).

Com base na equação proposta pelo NRC (2001) o NDT foi estimado, onde a constante 7 refere-se ao valor metabólico fecal:

$N D T(\%)=(P B D+C T D+E E D * 2,25)-7$

Os teores de proteína degradável no rúmen (PDR) foram estimados de acordo com recomendações do NRC (2001), através da seguinte equação:

$P D R=A+B *(K d / K d+K p)$ 
Onde: A - corresponde a fração solúvel em água; B - fração insolúvel em água e potencialmente degradável; Kd - taxa de degradação da fração B e $\mathrm{Kp}$ - taxa de passagem da $\mathrm{PB}$ pelo rúmen. Os valores de A (\%), B (\%) e Kd (\%/h) dos ingredientes utilizados, foram obtidos de Valadares Filho, Rocha Junior e Capelle (2002) e o valor do Kp utilizado foi de $5 \% / \mathrm{h}$.

$\mathrm{O}$ experimento foi delineado como um quadrado latino $5 \mathrm{X} 5$ (5 períodos e 5 tratamentos). Os procedimentos estatísticos foram realizados por intermédio do programa SAS (STATISTICAL ANALYSIS SYSTEM, 2001), adotando-se 0,05 como nível crítico de probabilidade. Nas variáveis $\mathrm{NH}_{3}$ e $\mathrm{pH}$ avaliou-se também o efeito de tempo, sendo essas variáveis analisadas como medidas repetidas no tempo. Caso houvesse efeito de tratamento pela ANOVA os contrastes ortogonais foram utilizados para partição específica dos efeitos de tratamento, comparando-se SAL versus PDR diário, PDR diário versus $\mathrm{PDR}$ frequência, $\mathrm{PDR}+$ versus $\mathrm{PDR}$ frequência e PDR- versus PDR frequência.

\section{Resultados e Discussão}

A disponibilidade média para massa de forragem seca total (MFST), massa de forragem seca potencialmente digestível (MFSpD), massa de folha verde (MFV), massa de folha seca (MFS), massa de colmo verde (MCV) e massa de colmo seco (MCS) foram de 6006, 4462, 1863, 854, 2413, $373 \mathrm{~kg} /$ ha, respectivamente. A disponibilidade de MFSpD média por animal durante o período experimental foi inferior $(2,55 \%$ do PV de MSpD) ao valor recomendado por Paulino et al. (2004) de 4 a $5 \%$ do PV de MSpD de forragem para que se proporcione equilíbrio entre a produção por animal e a produção por área, proporcionando aumento na eficiência de uso da forragem.

O valor médio de PB para Brachiaria brizantha cv. Marandu, no período de transição águas-seca, obtido neste trabalho foi de 9,23\% (Tabela 2). Foi possível verificar que o teor médio de $\mathrm{PB}$ da forragem esteve acima do valor de 7\%, relatado por Minson (1990) e Van Soest (1994) como sendo o teor mínimo de PB para que o crescimento dos microrganismos ruminais não seja comprometido.

Tabela 2. Teores médios de MS, PB, PDR, EE, FDN, FDA e NDT da Brachiaria brizantha cv. Marandu e dos suplementos, com base na matéria seca.

\begin{tabular}{lcccc}
\hline \multirow{2}{*}{ Item } & \multicolumn{3}{c}{ Suplementos } & \multirow{2}{*}{ Brachiaria brizantha $^{1}$} \\
\cline { 2 - 4 } & PDR & PDR +** & PDR -*** & 34,93 \\
MS (\%) & 88,66 & 88,66 & 87,19 & 9,23 \\
PB $^{2}$ & 23,01 & 29,12 & 13,89 & - \\
PDR $^{3 ; 4}$ & 64,58 & 68,13 & 61,05 & 1,79 \\
EE $^{2}$ & 3,78 & 3,4 & 3,93 & 72,66 \\
FDN $^{2}$ & 14,71 & 14,62 & 14,67 & 32,55 \\
FDA $^{2}$ & 10,07 & 10,47 & 8,94 & - \\
NDT (\%) & 88,03 & 87,27 & 88,73 & \\
\hline
\end{tabular}

${ }^{1}$ simulação de pastejo; ${ }^{2} \%$ da MS $3 \%$ do N total; ${ }^{4}$ Estimado segundo o NRC (2001).

*PDR: Suplemento formulado para atendimento das exigências de proteína degradável no rúmen de acordo com Valadares Filho, Paulino e Magalhães (2006);

**PDR +: Suplemento formulado com acréscimo de $10 \%$ das exigências de proteína degradável no rúmen;

***PDR -: Suplemento formulado com $10 \%$ a menos da exigência de proteína degradável no rúmen.

Fonte: Elaboração dos autores. 
Os consumos de matéria seca (CMS), os suplementos Sal vs. PDR diário, sendo que, forragem (CFO) e fibra em detergente neutro os animais do suplemento controle apresentaram $(\mathrm{CFDN})$ apresentaram diferença $(\mathrm{P}<0,05)$ entre maiores valores para essas características (Tabela 3$)$.

Tabela 3. Valores médios de consumos de matéria seca (CMS), matéria seca de forragem (CFO), proteína bruta (CPB), fibra em detergente neutro (CFDN) de bovinos em função dos suplementos PDR diário, PDR frequência, PDR ,+ PDR. -

\begin{tabular}{|c|c|c|c|c|c|c|c|c|c|c|}
\hline \multirow{2}{*}{ Item } & \multicolumn{5}{|c|}{ Suplementos } & \multirow{2}{*}{ CV (\%) } & \multicolumn{4}{|c|}{ Contraste $^{1}$} \\
\hline & Sal & PDR diário & PDR frequência & PDR + & PDR - & & SPDR & FREQ & $\mathrm{PF}+$ & PF- \\
\hline \multicolumn{11}{|c|}{$\mathrm{Kg} /$ dia } \\
\hline CMS & 9,06 & 6,19 & 5,70 & 6,19 & 7,10 & 16,78 & 0,0014 & 0,4837 & 0,4855 & 0,0574 \\
\hline $\mathrm{CFO}$ & 8,84 & 5,53 & 5,06 & 5,54 & 6,48 & 18,88 & 0,0005 & 0,4961 & 0,4910 & 0,0561 \\
\hline $\mathrm{CPB}$ & 0,80 & 0,68 & 0,64 & 0,76 & 0,71 & 13,37 & 0,0788 & 0,5789 & 0,0891 & 0,3149 \\
\hline CFDN & 6,75 & 4,17 & 3,83 & 4,20 & 4,78 & 17,20 & 0,0002 & 0,4797 & 0,4425 & 0,0635 \\
\hline \multicolumn{11}{|c|}{$\%$ do Peso Vivo } \\
\hline CMS & 2,35 & 1,56 & 1,43 & 1,55 & 1,81 & 19,37 & 0,0035 & 0,5614 & 0,5920 & 0,0964 \\
\hline $\mathrm{CFO}$ & 2,29 & 1,39 & 1,27 & 1,39 & 1,65 & 21,34 & 0,0010 & 0,5583 & 0,5786 & 0,0818 \\
\hline CFDN & 1,75 & 1,05 & 0,96 & 1,05 & 1,22 & 19,64 & 0,0004 & 0,5505 & 0,5370 & 0,0961 \\
\hline
\end{tabular}

$1 / \mathrm{SPDR}=\mathrm{SAL}$ versus $\mathrm{PDR}$ diário; $\mathrm{FREQ}=\mathrm{PDR}$ diário versus $\mathrm{PDR}$ frequência; $\mathrm{PF}+=\mathrm{PDR}$ frequência versus $\mathrm{PDR}+$;PF- $=$ PDR frequência versus PDR -

Fonte: Elaboração dos autores.

A suplementação múltipla na ordem de $0,3 \%$ PV com suplementos com teores de PB de 13,99\% (PDR -), 23,01\% (PDR diário e PDR frequência), $29,12 \%(\mathrm{PDR}+)$ proporcionou consumos relativos médios de matéria seca, em função do peso vivo de 2,35; 1,56; 1,43; 1,55 e1,81 \% para os suplementos Controle, PDR diário, PDR frequência, PDR +, PDR -, respectivamente. Além disso, verificou-se que os CMS, CFO e CFDN apresentaram diferença entre os suplementos Sal vs. PDR diário (Tabela 3).

Os valores médios de consumo relativo (\% de PV) obtidos no presente estudo foram inferiores aos encontrados por Goes (2004) para bovinos suplementados no período de transição águas-seca em pastagem com Brachiaria Brizantha. Goes (2004), avaliando suplemento múltiplo compostos com milho e farelo de soja (24\% PB) em diferentes níveis de suplementação, observou consumo médio, em função do peso vivo, de 2,45, 2,76 e 2,48 para os níveis $0,125 \%, 0,25 \%$ e $0,5 \%$ PV de suplementação, respectivamente.

$\mathrm{O}$ fornecimento com frequência controlada do suplemento não afetou o consumo de pasto e nutrientes. Resultados semelhantes foram encontrados por Farmer et al. (2004) e Moraes (2006). Farmer et al. (2004), avaliando dois suplementos (30\% PB) contendo 0 ou $30 \%$ de PDR na forma de ureia fornecidos diariamente ou em dias alternados, não observou diferença entre os tratamentos para consumo de forragem. Já Moraes (2006), avaliando a suplementação proteica e as frequências de suplementação diária e três vezes por semana para novilhos em pastejo no período de transição águas-seca, não observou diferença nos consumos de matéria seca e nutrientes entre as frequências avaliadas. Possível explicação para este fato, segundo Beaty et al. (1994), seria que animais suplementados diariamente ou três vezes por semana não apresentarem diferenças quanto ao tempo de pastejo. 
No entanto, Bohnert, Schauer e Delcurto (2002) observaram redução no consumo de pasto à medida que se reduziu a frequência de suplementação. De acordo com os autores, esta queda no consumo de pasto com a redução na frequência de suplementação pode ser em razão do efeito de substituição do pasto pelo suplemento, sendo mais pronunciada no evento da suplementação pela maior quantidade de suplemento ofertado aos animais. No entanto, este efeito substitutivo não foi observado no presente estudo.

Além disso, verificou-se diferença $(\mathrm{P}<0,05)$ para digestibilidade aparente da MS e FDN entre os suplementos (Sal vs. PDR diário). No entanto, não foi verificada diferença $(P>0,05)$ da digestibilidade aparente total entre os suplementos PDR diário vs PDR frequência; PDR frequência vs PDR+; PDR frequência vs PDR- (Tabela 4).

Tabela 4. Valores médios de coeficientes de digestibilidade aparente total (\%) da matéria seca (DMS), proteína bruta (DPB) e fibra em detergente neutro (DFDN) de bovinos em função dos suplementos PDR diário, PDR frequência, $\mathrm{PDR}+, \mathrm{PDR}-$

\begin{tabular}{|c|c|c|c|c|c|c|c|c|c|c|}
\hline \multirow{2}{*}{ Item } & \multicolumn{5}{|c|}{ Tratamento } & \multirow{2}{*}{ CV $(\%)$} & \multicolumn{4}{|c|}{ Contraste $^{1}$} \\
\hline & Sal & PDR diário & PDR frequência & SPDR & SPDR & & SPDR & FREQ & $\mathrm{PF}+$ & PF- \\
\hline \multicolumn{11}{|c|}{$(\%)$} \\
\hline MS & 55,64 & 49,51 & 48,69 & 48,16 & 48,91 & 6,27 & 0,0224 & 0,7173 & 0,8142 & 0,9248 \\
\hline $\mathrm{PB}$ & 44,93 & 50,74 & 52,87 & 57,11 & 46,74 & 17,03 & 0,3725 & 0,7200 & 0,4794 & 0,3111 \\
\hline FDN & 69,91 & 49,41 & 50,67 & 50,99 & 52,80 & 6,77 & 0,0117 & 0,1071 & 0,7510 & 0,8051 \\
\hline
\end{tabular}

1/ SPDR = SAL versus $\mathrm{PDR}$ diário; FREQ $=$ PDR diário versus $\mathrm{PDR}$ frequência; $\mathrm{PF}+=\mathrm{PDR}$ frequência versus $\mathrm{PDR}+$; $\mathrm{PF}-=\mathrm{PDR}$ frequência versus PDR -

Fonte: Elaboração dos autores.

A ausência de diferença $(\mathrm{P}>0,05)$ entre os suplementos para digestibilidade aparente total da MS e FDN, permite inferir que todos os suplementos avaliados proporcionaram aos microrganismos fermentadores de carboidratos estruturais quantidades de $\mathrm{N}$ suficientes para o atendimento de suas exigências e que a suplementação com fornecimento controlado (3X/semana) não prejudicou a digestibilidade da MS e FDN.

Resultados semelhantes ao presente estudo com relação à suplementação com frequência controlada foram verificados por Farmer et al. (2004) e Moraes (2006). No estudo realizado por Farmer et al. (2004), animais suplementados diariamente ou 2 vezes por semana apresentaram digestibilidade total da MS semelhantes. Segundo os mesmos autores a ausência de diferença entre os tratamentos demonstra a capacidade dos ruminantes em utilizar recursos fisiológicos como à reciclagem de nitrogênio para suprir nutrientes quando estes são fornecidos em uma menor frequência.

Com relação à digestibilidade da $\mathrm{PB}$ nos tratamentos avaliados, é possível verificar que apesar da ausência de diferença estatística $(\mathrm{P}>0,05)$ o suplemento PDR + proporcionou numericamente maior digestibilidade da PB. Este resultado, segundo Moraes (2006) pode indicar que neste tratamento os animais apresentaram maiores perdas de proteína na forma de amônia, o que pode ser indicativo de excesso de consumo de PDR. De fato, as maiores concentrações de amônia ruminal foram observadas para o tratamento PDR + (Tabela 5) e com consequente maior valor numérico (sem apresentar diferença estatística) de excreção urinária de nitrogênio na forma de ureia (Tabela 6). 
Tabela 5. Médias dos valores de $\mathrm{N}_{-} \mathrm{NH}_{3}(\mathrm{mg} / \mathrm{dL})$ no líquido ruminal, nos dias suplementados e não suplementados.

\begin{tabular}{|c|c|c|c|c|c|c|c|c|c|c|c|}
\hline \multirow[b]{2}{*}{ Item } & \multicolumn{6}{|c|}{ Tratamento $^{1}$} & \multirow[b]{2}{*}{$\mathrm{CV}(\%)$} & \multicolumn{4}{|c|}{ Contraste $^{1}$} \\
\hline & Tempo & SAL & $\begin{array}{l}\text { PDR } \\
\text { diário }\end{array}$ & $\begin{array}{c}\text { PDR } \\
\text { frequência }\end{array}$ & $\begin{array}{c}\text { PDR } \\
+\end{array}$ & $\begin{array}{c}\text { PDR } \\
-\end{array}$ & & SPDR & FREQ & $\mathrm{PF}+$ & PF- \\
\hline \multicolumn{12}{|c|}{ Dia Suplementado } \\
\hline \multirow[t]{2}{*}{$\mathrm{pH}$} & 0 & 6,43 & 6,65 & 6,66 & 6,63 & 6,69 & 2,64 & 0,9215 & 0,7677 & 0,6374 & 0,2118 \\
\hline & 4 & 6,16 & 6,37 & 6,40 & 6,38 & 6,53 & 3,37 & 0,8489 & 0,9115 & 0,3412 & 0,2654 \\
\hline \multirow[t]{2}{*}{$\mathrm{NH}_{3}$} & 0 & 10,72 & 15,02 & 14,60 & 15,98 & 12,73 & 22,09 & 0,9707 & 0,5392 & 0,2321 & 0,1064 \\
\hline & 4 & 7,98 & 20,30 & 21,03 & 30,48 & 18,65 & 21,74 & 0,7056 & 0,0357 & 0,0065 & 0,0001 \\
\hline \multicolumn{12}{|c|}{ Dia não Suplementado } \\
\hline \multirow[t]{2}{*}{$\mathrm{pH}$} & 0 & 6,65 & 6,54 & 6,55 & 6,61 & 6,65 & 3,69 & 0,9289 & 0,7220 & 0,8585 & 0,8461 \\
\hline & 4 & 6,65 & 6,49 & 6,53 & 6,54 & 6,60 & 4,26 & 0,2647 & 0,8456 & 0,3533 & 0,0024 \\
\hline \multirow[t]{2}{*}{$\mathrm{NH}_{3}$} & 0 & 7,54 & 17,91 & 14,65 & 19,97 & 16,47 & 21,22 & 0,2596 & 0,0789 & 0,1998 & 0,0003 \\
\hline & 4 & 7,98 & 21,09 & 17,37 & 16,93 & 14,52 & 19,60 & 0,8188 & 0,9797 & 0,7411 & 0,6339 \\
\hline \multicolumn{12}{|c|}{$\mathrm{pH}$} \\
\hline \multicolumn{2}{|c|}{ Dia suplementado } & 6,30 & 6,51 & 6,53 & 6,51 & 6,61 & 3,01 & 0,8509 & 0,8078 & 0,3505 & 0,1363 \\
\hline \multicolumn{2}{|c|}{ Dia não suplementado } & 6,65 & 6,52 & 6,54 & 6,58 & 6,63 & 3,98 & 0,7990 & 0,7827 & 0,6871 & 0,5919 \\
\hline \multicolumn{12}{|c|}{$\mathrm{NH}_{3}$} \\
\hline \multicolumn{2}{|c|}{ Dia suplementado } & 9,35 & 17,66 & 17,82 & 23,23 & 15,69 & 21,92 & 0,8718 & 0,1497 & 0,0312 & 0,0001 \\
\hline \multicolumn{2}{|c|}{ Dia não suplementado } & 7,76 & 19,50 & 16,01 & 18,45 & 15,50 & 20,41 & 0,1008 & 0,2225 & 0,1047 & 0,0001 \\
\hline
\end{tabular}

1/ SPDR $=$ SAL versus $\mathrm{PDR}$ diário; FREQ $=$ PDR diário versus $\mathrm{PDR}$ frequência; $\mathrm{PF}+=$ PDR frequência versus $\mathrm{PDR}+$; $\mathrm{PF}-=\mathrm{PDR}$ frequência versus PDR -

Fonte: Elaboração dos autores.

Tabela 6. Valores médios de compostos nitrogenados excretados na urina (NUR) e sérico (NS), de bovinos em função dos suplementos PDR diário, PDR frequência, PDR +, PDR -

\begin{tabular}{|c|c|c|c|c|c|c|c|c|c|c|}
\hline \multirow[b]{2}{*}{ Item } & \multicolumn{5}{|c|}{ Tratamento $^{1}$} & \multirow[b]{2}{*}{$\mathrm{CV}(\%)$} & \multicolumn{4}{|c|}{ Contraste $^{1}$} \\
\hline & SAL & $\begin{array}{c}\text { PDR } \\
\text { diário } \\
\end{array}$ & $\begin{array}{c}\text { PDR } \\
\text { frequência }\end{array}$ & PDR + & PDR - & & SPDR & FREQ & $\mathrm{PF}+$ & PF- \\
\hline $\mathrm{NUR}^{2}$ & 10,15 & 8,12 & 10,01 & 15,82 & 13,53 & 21,41 & 0,6252 & 0,5521 & 0,1562 & 0,4817 \\
\hline $\mathrm{NS}^{3}$ & 10,5 & 23,25 & 22,75 & 31,25 & 18,00 & 27,14 & 0,0012 & 0,8775 & 0,0177 & 0,1572 \\
\hline
\end{tabular}

1/ SPDR = SAL versus $\mathrm{PDR}$ diário; FREQ $=$ PDR diário versus $\mathrm{PDR}$ frequência; $\mathrm{PF}+=\mathrm{PDR}$ frequência versus $\mathrm{PDR}+$; PF- =PDR frequência versus $\mathrm{PDR}-;{ }^{2} / \mathrm{g} / \mathrm{dia} ;{ }^{3} / \mathrm{mg} / \mathrm{dL}$.

Fonte: Elaboração dos autores.

$\mathrm{O} \mathrm{pH}$ ruminal apresentou diferença $(\mathrm{P}<0,05)$ entre os suplementos PDR frequência $(6,53)$ vs. PDR- $(6,60)$ no tempo 4 horas em dia de não suplementação. No entanto, não foram observadas diferenças significativas $(\mathrm{P}>0,05)$ para o $\mathrm{pH}$ ruminal entre os suplementos Sal vs. PDR diário, PDR diário vs. PDR frequência e PDR frequência vs. PDR+, para o tempo de mensuração e também para os diferentes dias da semana. Os valores médios de $\mathrm{pH}$ obtidos nos animais dos suplementos SAL e PDR diário foram 6,48 e 6,51, respectivamente (Tabela 5).

Segundo Fox et al. (1992), o pH ótimo para a síntese microbiana é de 6,46, apresentando prejuízo severo à degradação de parede celular das forragens consumidas quando o pH diminui abaixo de 5,43.

No presente estudo, os valores médios de $\mathrm{pH}$ 
obtidos nos dias suplementados e não suplementados estiveram sempre acima de 6,0. Apesar dos animais dos tratamentos PDR frequência, PDR +, PDR receberem maiores quantidades de suplementos nos dias de suplementação, os valores médios de $\mathrm{pH}$ se mantiveram praticamente estáveis entre os dias de suplementação e não.

A concentração de amônia ruminal dos animais suplementados apresentou diferença $(\mathrm{P}<0,05)$ entre os suplementos PDR frequência vs. Sal, PDR+ e PDR- 4 horas após o fornecimento dos suplementos (Tabela 5).. Os valores médios no dia suplementado, tempo 4, foram de 20,30, 21,03, 30,48, 18,65, $7,99 \mathrm{mg} / \mathrm{dL}$ de $\mathrm{N}^{-\mathrm{NH}_{3}}$ no líquido ruminal para os tratamentos PDR diário, PDR frequência, PDR +, PDR - e SAL, respectivamente. Uma das observações que podem ser feitas entre os tratamentos PDR diário e PDR frequência é que a maior quantidade de suplemento ingerido pelos animais do tratamento PDR frequência foi suficiente para elevar $(\mathrm{P}<0,05)$ a concentração de $\mathrm{N}-\mathrm{NH}_{3}$ ruminal. No entanto, como já foi ressaltado no trabalho, essa maior quantidade de suplemento não foi suficiente para baixar o valor de $\mathrm{pH}$ consideravelmente.

Segundo Bohnert, Schauer e Delcurto (2002) os ruminantes podem ser hábeis em conservar $\mathrm{N}$ por longos períodos, possivelmente através de mudanças na permeabilidade do trato gastrointestinal a ureia e/ou pela regulação da excreção renal, mantendo o fornecimento de $\mathrm{N}$ entre os intervalos de suplementação. Tal fato sugere que a amônia ruminal entre os eventos de suplementação de animais suplementados com frequência controlada, pode ser mantida em concentrações similares a de animais suplementados diariamente, como resultado de um ativo sistema de reciclagem endógena de $\mathrm{N}$ destes animais, o que permite manter a digestão da fibra (BEATY et al., 1994).

Além disso, os suplementos PDR frequência e PDR- apresentaram diferença $(\mathrm{P}<0,05)$ na concentração de $\mathrm{N}_{-} \mathrm{NH}_{3}$ ruminal no tempo 0 hora no dia não suplementado. De forma geral, os valores médios de $\mathrm{N}-\mathrm{NH}_{3}$ dos tratamentos PDR diário, PDR frequência, PDR + e PDR -, independente do dia da semana, permaneceram na sua grande maioria, dentro da faixa de 10 a $20 \mathrm{mg}$ de $\mathrm{N}-\mathrm{NH}_{3} / \mathrm{dL}$ de líquido ruminal descrita por Leng (1990) como sendo a concentração ideal de $\mathrm{N}-\mathrm{NH}_{3}$ para a máxima síntese de proteína bruta microbiana em regiões tropicais. Com relação ao tratamento controle (SAL), o valor médio dos períodos experimentais foi de 9,15 mg de $\mathrm{N}-\mathrm{NH}_{3} / \mathrm{dL}$ de líquido ruminal. Este valor é próximo ao limite inferior da faixa ideal de $\mathrm{N}_{-} \mathrm{NH}_{3}$, preconizada por Leng (1990) para a síntese microbiana.

As concentrações de NUR não foram influenciadas pelo tipo do tratamento $(\mathrm{P}>0,05)$, embora, as concentrações de NS apresentaram diferença $(\mathrm{P}<0,05)$ entre os suplementos Sal vs. PDR frequência, PDR frequência vs. PDR- (Tabela 6).

O NS tem sido frequentemente utilizado com a finalidade de fornecer informações adicionais do status da nutrição proteica de ruminantes, envolvendo a resposta deste a determinada dieta (VALADARES et al., 1997). Os valores médios observados de NS para os tratamentos SAL, PDR diário, PDR frequência, PDR + e PDR foram $10,5,23,25,22,75,31,25$ e $18,00 \mathrm{mg} / \mathrm{dL}$, respectivamente (Tabela 6). Valadares et al. (1997) verificaram, por intermédio de análise de regressão, que a máxima produção microbiana correspondeu a concentrações de NS variando de 13 a $15 \mathrm{mg} / \mathrm{dL}$, o que provavelmente representaria o limite a partir do qual estaria ocorrendo perda de proteína. Já segundo Oliveira, Valadares e Valadares Filho (2001) o limite para que não ocorram perdas de $\mathrm{N}$ é de 19 a $20 \mathrm{mg} /$ dL. Observa-se nos valores médio obtidos para NS no presente estudo (Tabela 6), somente o tratamento SAL apresentou valor médio inferior aos descritos por Valadares et al. (1997). No entanto, quando comparado ao valor limite descritos por Oliveira, Valadares e Valadares Filho (2001), somente os tratamentos PDR diário, PDR frequência e PDR + apresentaram valores médios superiores. 
Quando são comparados os tratamentos SAL e PDR diário, verifica-se que o valor médio de NS do tratamento SAL é inferior $(\mathrm{P}<0,05)$. Segundo Harmeyer e Martens (1980), a concentração de NS tem relação positiva com o consumo de $\mathrm{N}$.

Já com relação aos tratamentos PDR + e PDR frequência, é importante ressaltar que o tratamento PDR + apresentou maior $(\mathrm{P}<0,05)$ concentração de NS quando comparado ao tratamento PDR frequência. Isso provavelmente é resultado do maior aporte de PDR do suplemento, que provocou altos níveis de $\mathrm{N}_{-} \mathrm{NH}_{3}$ ruminal que em parte não foi aproveitado pelos microrganismos ruminais. Este não aproveitamento possivelmente resultou em maior absorção de $\mathrm{N}$ pela parede do rúmen indo para corrente sanguínea, e posteriormente sendo perdido por via urinária na forma de ureia. Esta explicação, apesar de ter fundamento, não pode ser totalmente comprovada, pois não foi verificada diferença entre os tratamentos PDR frequência e PDR + com relação ao NUR.

\section{Conclusões}

O fornecimento de suplementos múltiplos com acréscimo ou redução em $10 \%$ nas exigências de PDR dos animais e com frequência controlada durante o período o de transição águas-seca não influencia o pH e a concentração de amônia ruminal e o consumo e digestibilidade da matéria seca e dos nutrientes. Essa estratégia de suplementação pode ser fornecida para bovinos durante o período de transição águas-seca, visto que não prejudica as características nutricionais dos animais.

\section{Referências}

ADAMS, D. C. Effect of time of supplementation on performance, forage intake and grazing behavior of yearling beef steers grazing Russian wild ryegrass in the fall. Journal of Animal Science, Champaign, v. 61, n. 5, p. 1037-1042, 1985.

BEATY, J. L.; COCHRAN, R. C.; LINTZENICH, B. A.; VANZANT, E. S.; MORRILL, J. L.; BRANDT, R. T.;
JOHNSON, D. E. Effect of frequency of supplementation and protein concentration in supplements on performance and digestion characteristics of beef cattle consuming low-quality forages. Journal of Animal Science, Champaign, v. 72, n. 9, p. 2475-2486, 1994.

BOHNERT, D. W.; SCHAUER, C. S.; DELCURTO, $\mathrm{T}$. Influence of rumen protein degradability and supplementation frequency on performance and nitrogen use in ruminants consuming low-quality forage: Cow performance and efficiency of nitrogen use in wethers. Journal of Animal Science, Champaign, v. 80, n. 6, p. 1629-1637, 2002.

CASALI, A. O.; DETMANN, E.; VALADARES FILHO, S. C.; PEREIRA, J. C.; HENRIQUES, L. T.; FREITAS, S. G.; PAULINO, M. F. Influência do tempo de incubação e do tamanho de partículas sobre os teores de compostos indigestíveis em alimentos e fezes bovinas obtidos por procedimentos in situ. Revista Brasileira de Zootecnia, Viçosa, MG, v. 37, n. 2, p. 335-342, 2008.

DETMANN, E.; PAULINO, M. F.; ZERVOUDAKIS, J. T.; VALADARES FILHO, S. C.; EUCLYDES, R. F.; LANA, R. P.; QUEIROZ, D. S. Cromo e indicadores internos na estimação do consumo de novilhos mestiços, suplementados, a pasto. Revista Brasileira de Zootecnia, Viçosa, MG, v. 30, n. 5, p. 1600-1609, 2001.

FARMER, C. G.; WOODS, B. C.; COCHRAN, R. C.; HELDT, J. S.; MATHIS, C. P.; OLSON, K. C.; TITGEMEYER, E. C.; WICKERSHAM, T. A. Effect of supplementation frequency and supplemental urea level on dormant tallgrass-prairie hay intake and digestion by beef streers and prepartum performance of beef cows grazing dormant tallgrass-prairie. Journal of Animal Science, Champaign, v. 82, n. 3, p. 884-894, 2004.

FOX, D. G.; SNIFFEN, C. J.; O'CONNOR, J. D.; RUSSELL, J. B.; VAN SOEST, P. J. A net carbohydrate and protein system for evaluating cattle diets: III. Cattle requirements and diet adequacy. Journal of Animal Science, Champaign, v. 70, n. 11, p. 3578-3596, 1992.

GOES, R. H. T. B. Sistema de recria de novilhos a pasto com diferentes niveis e frequências de suplementação, na região amazônica. 2004. Tese (Doutorado em Zootecnia) - Programa de Pós-Graduação em Zootecnia, Universidade Federal de Viçosa, Viçosa, MG.

HARMEYER, J.; MARTENS, H. Aspects of urea metabolism in ruminants with reference to the goat. Journal of Dairy Science, Savoy, v. 63, n. x, p. 17071728, 1980.

LENG, R. A. Factors affecting the utilization of "poorquality" forages by ruminants particularly under tropical conditions. Nutrition Research Review, Cambridge, v. 3, n. 3, p. 277-303, 1990. 
MINSON, D. J. Forage in ruminant nutrition. New York: Academic Press, 1990. 483 p.

MORAES, E. H. B. K. Desempenho e exigências de energia, proteina e minerais de bovinos de corte em pastejo, submetidos a diferentes estratégias de suplementação. 2006. Tese (Doutorado em Zootecnia) Programa de Pós-Graduação em Zootecnia, Universidade Federal de Viçosa, Viçosa, MG.

NATIONAL RESEARCH COUNCIL - NRC. Nutrients requirements of dairy cattle. 7. ed. Washington, D. C.: National Academy Press, 2001. 381 p.

OLIVEIRA, A. S.; VALADARES, R. F. D.; VALADARES FILHO, S. C.; CECON, P. R.; RENNÓ, L. N.; QUEIROZ, A. C.; CHIZZOTTI, M. L. Produção de proteína microbiana e estimativas das excreções de derivados de purinas e de ureia em vacas lactantes alimentadas com rações contendo diferentes níveis de compostos nitrogenados não-proteicos. Revista Brasileira de Zootecnia, Viçosa, MG, v. 30, n. 5, p. 16211629, 2001.

PAULINO, M. F.; FIGUEIREDO, D. M.; MORAES, E. H. T. B.; PORTO, M. O.; ACEDO, T. S.; VILLELA, S. D. J.; VALADARES FILHO, S. C. Suplementação de bovinos em pastagens: uma visão sistêmica. In: SIMPÓSIO DE PRODUÇÃO DE GADO DE CORTE, 4., 2004, Viçosa. Anais... Viçosa: SIMCORTE, 2004. p. 93-139.

REIS, R. A.; MELO, G. M. P.; BERTIPAGLIA, L. M. A.; OLIVEIRA, A. P. Otimização da utilização da forragem disponível através da suplementação estratégica. In: REIS, R. A.; SIQUEIRA, G. R.; BERTIPAGLIA, L. M. A.; OLIVEIRA, A. P.; MELO, G. M. P.; BERNARDES, T. F. (Ed.). Volumosos na produção de ruminantes. Jaboticabal: FUNEP, 2005. p. 187-238.

RUSSELL, J. B.; O'CONNOR, J. D.; FOX, D. G. ; VAN SOEST, P. J.; SNIFFEN, C. J. A net carbohydrate and protein system for evaluation cattle diets: ruminal fermentation. Journal of Animal Science, Champaign, v. 70, n. 12, p. 3551-3581, 1992.
SALIBA, E. O. S.; NANJARO, A.; FERREIRA, W. M.; RODRIGUEZ, N. M.; VELOSO, D. P.; CAPANEMA, E.; SALIBA, M. S. Avaliação da lignina de madeira moída do Pinus e da lignina purificada e enriquecida do Eucaliptus Grandis (LIPE®), como indicadores externos em experimentos de digestibilidade aparente para coelhos em crescimento. In: TELECONFERÊNCIA SOBRE INDICADORES EM NUTRIÇÃO ANIMAL, 1., 2005, Belo Horizonte. Anais... Belo Horizonte: Escola de Veterinária/UFMG, 2005. p. 34-35.

SILVA, D. J.; QUEIROZ, A. C. Análise de alimentos: métodos químicos e biológicos. 3. ed. Viçosa: UFV, 2002. $235 \mathrm{p}$.

STATISTICAL ANALYSIS SYSTEM INSTITUTE SAS. Statistical Analysis Software (SAS). Cary: SAS Institute, 2001.

VALADARES FILHO, S. C.; PAULINO, P. V. R.; MAGALHÃES, K. A. Exigências nutricionais de zebuinos e tabela de composição de alimentos. Viçosa: UFV, 2006. 142 p.

VALADARES FILHO, S. C.; PAULINO, P. V. R.; MAGALHÃES, K. A. Exigências nutricionais de zebuínos e tabela de composição de alimentos. Viçosa: UFV, 2006. 142 p.

VALADARES, R. F. D.; BRODERICK, G. A.; VALADARES FILHO, S. C.; CLAYTON, M. K. Effect of replacing alfalfa silage with high moisture corn on ruminal protein synthesis estimated from excretion of total purine derivatives. Journal of Dairy Science, Cambridge, v. 82, n. 11, p. 2686-2696, 1999.

VALADARES, R. F. D.; GONÇALVES, L. C.; RODRIGUEZ. N. M.; VALADRES FILHO, C. C.; SAMPAIO, I. B. M. Níveis de proteína bruta em dietas de bovinos. 4. Concentração de amônia ruminal, uréia plasmática e excreções de creatinina. Revista Brasileira de Zootecnia, Viçosa, v. 26, n. 6, p. 1270-1278, 1997.

VAN SOEST, P. J. Nutritional ecology of the ruminant. $2^{\text {th }}$ ed. Ithaca: Cornell University, 1994. 476 p. 